\title{
Köpeklerde femur ve tibia kırıklarının sağaltımında kilitli intramedullar pin yönteminin klinik ve radyolojik değerlendirilmesi
}

\author{
Kısmet Salan ANAÇ ${ }^{1, a}$, Ümit KAYA ${ }^{1, b^{*}}$, İlker ŞEN ${ }^{2, c}$ \\ ${ }^{l}$ Ankara Üniversitesi Veteriner Fakültesi Cerrahi Anabilim Dall, Ankara, Türkiye \\ ${ }_{2}^{2}$ Cumhuriyet Üniversitesi Veteriner Fakültesi Cerrahi Anabilim Dall, Sivas, Türkiye \\ ORCID:0000-0002-5617-0434 ${ }^{a} ; 0000-0001-9869-9072^{b} ; 0000-0001-8288-4871^{c}$
}

\begin{abstract}
MAKALE BİLGISI: $\quad$ ÖZET:
ARTICLE

INFORMATION:

Geliş / Received:

29 Temmuz 19

29 July 19

Kabul / Accepted:

28 Kasim 19

28 November 19

$\mathrm{Bu}$ çalışmanın amacı veteriner ortopedide sıkça kullanılan intramedullar pin uygulamalarına bir alternatif getirmek ve kilitli intramedullar pin yöntemiyle ilgili deneyimler kazanmaktır. Çalıșma materyalini, femur ya da tibiasında kırık tespit edilen 10 köpek oluşturdu. Çalışmada rutin yumuşak doku ve ortopedi setlerinin yanında farklı uzunluk ve çaplarda kilitli intramedullar pinler ve kilitli intramedullar pin uygulama seti kullanıldı. Çalışma materyalini oluşturan 10 olgudan belirlenen 11 kırı̆̆ın 5'i (\%46) transversal kırık, 3’ü (\%27) oblik kırık, 3’ü de (\%27) parçalı kırık olarak sınıflandırılmıştır. Olgu no 9 ve 10 haricinde hiçbir olguda komplikasyona rastlanmadı. Komplikasyonun gözlenmediği olgularda kırık iyileşmesinden sonra interlocking pin, ilgili kemiğin medullasında bırakıldı ve klinik olarak bir probleme neden olmadığı gözlendi. Interlocking pinler köpeklerin femur ve tibia gibi uzun kemiklerinde meydana gelen diyafizer kırıklarında kullanılabilir. Stabil olmayan kırıklar da dahil, fonksiyonel iyileşme sonuçları ve düşük komplikasyon oranlarıyla ilişkilendirildiğinde, uzun kemiklerin diyafizer kırıklarında interlocking pinlerin kullanımı desteklenmektedir. Sonuç olarak interlocking pin ile sağaltım metodu, femur ve tibianın diyafizer kırıklarında alternatif bir sağaltım metodu olarak düşünülebilir
\end{abstract}

Anahtar Sözcükler:

Femur

İnterlocking pin

Kirık

Köpek

Tibia

Keywords:

Dog

Femur

Fracture

Interlocking nail

Tibia

\section{Clinical and radiological evaluation of the treatment of femoral and tibial fractures with the use of interlocking nails in dogs}

ABSTRACT:

The aim of this study was to introduce an alternative method to intramedullar pinning which are used frequently in veterinary orthopeadics and improve the experience of treatment with the use of interlocking nailing method. The study material involved 10 dogs with femoral and tibial fractures. Interlocking nailing application set, routine surgical and orthopeadical sets were used in this study. Within 11 fractures in 10 cases were classified as transversal fracture in 5 cases $(46 \%)$, oblique fracture in 3 cases $(27 \%)$, communited fracture in 3 cases $(27 \%)$. No complication was observed in all cases but case no 2, 9 and 10. Interlocking nails were left in the bones in all cases except one case. Interlocking nails can be used in diaphiseal femoral and tibial fractures in dogs. It is supported to use of interlocking nailing even in unstable diaphyseal fractures in dogs when considered functional healing results and low complication rates. As a result, using of interlocking nailing can be considered as an alternative treatment method to other intramedullary treatments in femoral and tibial fractures in dogs.

How to cite this article: Anaç KS, Kaya Ü, Şen İ: Köpeklerde femur ve tibia kırıklarının sağaltımında kilitli intramedullar pin yönteminin klinik ve radyolojik değerlendirilmesi. Veteriner Hekimler Dernegi Dergisi, 91(1): 36-43, 2020, DOI: 10.33188/vetheder.598043

\footnotetext{
* Sorumlu yazar eposta adresi / Corresponding author e-mail address: vet.dr.umit@gmail.com
} 


\section{Giriş}

Interlocking Pin; kırıkların sağaltımında, medullar kanal içerisine, üzerinde bulunan vida deliklerinden korteks-pin-korteks geçişli vidalarla sabitlenen, intramedullar bir pin çeşididir $(1,7)$.

Medullar kanala uygulanan intramedullar pin, bükülme kuvvetlerini, pinin vidalarla sabitlenmesi ise makaslama, kompresyon, torsiyon ve gerilme kuvvetlerini engeller $(2,5,9)$.

Interlocking pinler humerus, femur veya tibianın özellikle diyafizinde meydana gelen kırıklarında kullanılır $(5,6,9)$. Kısa ve orta dönem iyileşme beklenen ve postoperatif bakımın önemli olduğu köpeklerde endike, Radius için ise kontrendikedir $(5,6)$.

Interlocking pinler uzun kemiklerin distal ve proksimal bölümleri haricindeki bütün kırık tiplerinde uygulanabilir. Özellikle çok parçalı, maddi kayıplı kırıklar ve nonunionlarda başarıyla kullanıldığ rapor edilmiştir (7, $8)$.

Pinler statik ve dinamik olmak üzere iki şekilde uygulanabilir. Kemiğin distal ve proksimal fragmentlerinin her ikisine de pin üzerinde bulunan vida deliklerinden ikişer vida uygulanırsa statik, her iki kırık fragmentine de birer vida uygulanırsa, dinamik interlocking çivileme olur. Parçalı, maddi kayıplı kırıklarda statik, transversal ve kısa oblik kırıklarda ise dinamik çivileme önerilir $(1,7)$.

Pinin distal ucunu metafiz boyunca ilerletme zorunluluğu olmadığından, kırık uçlarında malpozisyon şekillenme riski, ekleme ve büyüme plaklarına zarar verme riski azalır $(4,7)$.

Interlocking çivilemede kullanılan pinler Steinmann pinlerden daha kalın olduğu için bükülme kuvvetini engellemede daha başarılıdır (9).

Kemiğin kırık hattına yakın bölümünde, incelme ve buna bağlı olarak kırık oluşma riski varsa, interlocking pinler bölgeye plaktan daha başarılı şekilde uygulanırlar. İyileşme sürecinde kallus oluşumu daha azdır ve anatomik yapıyı korurken aksial hizalamayı da sağlayarak açılanmanın önüne geçer $(4,6)$.

Interlocking pinler uygulandıkları bölge gereği medullar kanal içerisine yerleştirildiklerinden, plak uygulamalarında karşılaşılan aseptik gevşeme gibi komplikasyonların önüne geçilmiş olur. Aynı zamanda genç hayvanların distal femur kırıklarında uygulama kaynaklı büyüme plağının erken dönemde kapanma riskinin de önüne geçer (1).

Kırık iyileşme süreci ilerledikçe uygulanan implant ve kemik arasındaki yük dağılımı kemik yönüne kayar. Bunun sebebi kallus oluşumu ile immobilizasyonun artmasıdır. Böylece implant üzerine binen stres azalır ve implanta bağlı oluşabilecek herhangi bir komplikasyon riski de en aza indirilmiş olur. Ayrıca interlocking pinleri kilitlemek için kullanılan vidalar kırık hattına uzak şekilde uygulanarak fragmentlerin maruz kalacağı aşırı stresten kaçınılmış olur (1).

Pinde bulunan vida delikleri, pinin direncini azaltır. Vida delikleri kırık hattına yakın olursa kemiğin ve implantın kırılma ihtimali ortaya çıkar, vidalar kırık hattına $2 \mathrm{~cm}$ 'den daha yakına uygulanırsa stres oluşturur (9).

Interlocking pinin çapı, uygulanacak kemiğin çapına uygun olarak seçilmelidir. Uygun olmayan çapta pin kullanılması, pin üzerinde bulunan vida deliklerinin kırık hattı üzerine denk gelmesi pinde kırılmalara neden olur. İmplantta kırık oluşumu daha çok distalde alt alta bulunan iki deliğin proksimalde yer alanından gerçekleşir (1).

Interlocking pin ve vidalarının özel ekipmanlarla uygulanabilir olması, sadece diyafiz kırıklarının sağaltımında kullanılabilmesi gibi dezavantajları vardır (1).

Interlocking pinlerin en zayıf noktaları vida delikleridir. Interlocking pinler, güçlendirilmek için daha küçük vida delikleri ile üretilmiştir, daha küçük vidalar kullanıldığında implant hatalarıyla daha az karşılaşılmıştır (5).

Bu çalışmada, veteriner ortopedide sıkça kullanılan intramedullar pin uygulamalarına bir alternatif oluşturmak, interlocking pin ile sağaltım yöntemiyle ilgili deneyimler kazanmak ve kazanılan deneyimleri klinisyen veteriner hekimlerle paylaşmak amaçlanmıştır.

\section{Gereç ve Yöntem}

Çalışma materyalini, femur ya da tibiasında kırık tespit edilen 10 köpek oluşturdu. Çalışmada rutin yumuşak doku ve ortopedi setlerinin yanında farklı uzunluk ve çapta interlocking pinler (Tablo 1) ve interlocking pin uygulama 
seti kullanıldı.

Tablo 1: Interlocking pin çap ve uzunlukları.

Table 1: Diameter and length of interlocking pins.

\begin{tabular}{cc}
\hline Çap (mm) & Uzunluk (mm) \\
\hline 4,5 & $130-160$ \\
6,0 & $130-190$ \\
8,0 & $150-230$
\end{tabular}

\section{Preoperatif Klinik ve Radyografik Muayene:}

Yapılan klinik muayene sonucunda arka ekstemitelerinde topallık, femur ve tibia bölgesinde ağrı, şişlik, anormal hareket, krepitasyon ve deformasyon tespit edilen köpeklerde hem tanı için ilgili bölgenin, hem de kullanılacak olan pin uzunluğu ve çapına karar vermek için kontralateral ekstremitenin mediolateral ve anterioposterior radyografileri alındi.

Kullanılacak interlocking pinin boyunu tam belirleyebilmek için kontralateral taraftaki sağlam kemiğin radyografisinden ölçümler yapıldı. Kemiğin medullar kanalına uyabilecek en geniş çapta, kırık olan kemiğin normal uzunluğuna uygun olacak şekilde pin şeçildi.

\section{Anestezi:}

Sedasyon için intramuskuler yolla $40 \mu \mathrm{g} / \mathrm{kg}$ medetomidin hidroklorür enjeksiyonunu takiben $10-15 \mathrm{dk}$ sonra genel anestezi oluşturmak için yine intramuskuler yolla $10 \mathrm{mg} / \mathrm{kg}$ ketamin hidroklorür, analjezi için ise deri altı yolla $0,2 \mathrm{mg} / \mathrm{kg}$ meloksikam uygulandı. Preoperatif antibiyotik olarak kas içi yolla $25 \mathrm{mg} / \mathrm{kg}$ amoksisilin uyguland.

\section{Uygulama Prosedürü:}

Femura cerrahi yaklaşım; Femur diyafizine lateral yaklaşım uygulandı. Deri altı yağ doku ve süperfisiyal fascia deri ensizyonu ile aynı hatta ve uzunlukta kesildi ve ekarte edildi. Fascia lata geçildikten sonra, femur diafizinin kaudalinde yer alan M. biceps femoris ve kranialinde yer alan M. vastus lateralis arasındaki fasiyal aponeurotik septum ensize edildi. Kaslar ekarte edilerek femurun diafizine ulaşıldı.

Tibiaya cerrahi yaklaşım; Tibianın diyafizine kraniomedialden yaklaşıldı. Deriye kraniomedialden tibianın eksenine paralel bir deri ensizyonu yapıldı. Deri altı yağ doku ve superfisiyal fasia deri ensizyonu ile aynı hatta ve uzunlukta kesildi ve ekarte edildi. Vena safena ve safenöz sinire zarar vermekten kaçınarak tibianın diyafizine ulaşıldı.

Kırık hattına ulaşıldıktan sonra, medullar kanal, seçilen pin çapına ve uzunluğuna uygun şekilde reamer ile genişletildi. Pin, medullar kanala yerleştirilerek, proksimalde sistemin uzatma aparatı ile bağlantısı yapıldı. Distal fragmentin redüksiyonu yapıldıktan sonra pin, distale doğru ilerletildi. Yeteri kadar ilerletildikten sonra, sistemin klavuzu eklendi. Vida uygulama kılavuzu ile pin üzerindeki deliklere denk gelen noktalarından dril yardımıyla delikler açıldı.

Distal fragmente vidalar uygulandıktan sonra kemiğe rotasyon yaptırılarak pinin de aynı şekilde rotasyon hareketini gösterip göstermediği kontrol edildi. Rotasyonel ve aksiyel hizalanma kontrol edildikten sonra proksimal fragmente de vidalar uygulandi.

Kemiğin çatlaması ve pinin kemiği kırması gibi komplikasyonları önlemek için vidalar mümkün olduğunca kırık hattından uzağa uygulandı. Bütün vidalar uygulandıktan sonra Interlocking çivileme sisteminin aparatları pinden ayrıldı. Deri altı dokular ve deri rutin şekilde kapatıldı. 


\section{Post Operatif Bakım:}

Kırığın redüksiyonu ve uygulanan implantın konumunu değerlendirmek için post operatif radyografiler alındı. Postoperatif muayene ve kontroller operasyondan sonra 0 . gün 10. gün, 30. gün ve 45. günde yapıld1.

Post operatif antibiyoterapi 1 hafta süreyle uygulandı. Yara hattı 10 gün süreyle, yumuşak bandaj uygulamasıyla korundu. Hareket kısıtlaması önerildi. Postoperatif 10. günün sonunda dikişler alındı ve kontrollü yürüyüşlere izin verildi.

İnterlocking pin kırık iyileşmesi sonrasında da yerinde bırakıldı.

Kırık iyileşmesinin değerlendirmeleri, Modifiye Hannover Veteriner Yüksek Okulu Küçük Hayvan Kliniği kırık sağaltımı değerlendirme skalası, Aslanbey' in (2002) önerdiği kırık iyileşmesinin klinik değerlendirilmesi kriterlerine göre yapıldı (Tablo 2).

Tablo 2: Modifiye Hannover Veteriner Yüksek Okulu kırık sağaltımı değerlendirme skalası.

Table 2: Modified fracture treatment evaluation scale of Faculty of Veterinary Medicine Hannover.

\begin{tabular}{|c|c|c|c|}
\hline & Kırığın Radyografik Görünümü & $\begin{array}{c}\text { Ekstremitenin Klinik } \\
\text { Görünümü }\end{array}$ & $\begin{array}{c}\text { Eklemlerin Radyografik Ve } \\
\text { Klinik Görünümü }\end{array}$ \\
\hline Çok İyi & Düzgün kemik kaynaması & $\begin{array}{c}\text { Tam ekstremite foksiyonu, } \\
\text { topallık yok }\end{array}$ & $\begin{array}{c}\text { Artritik değişiklik yok (-), } \\
\text { eklem hareketi çok iyi }\end{array}$ \\
\hline İyi & $\begin{array}{l}\text { Tam olmayan kaynama, yinede iyi } \\
\text { bir bütünlük }\end{array}$ & $\begin{array}{c}\text { Tam ekstremite foksiyonu, } \\
\text { topallık yok }\end{array}$ & $\begin{array}{c}\text { Artritik değişiklik çok az }(+), \\
\text { eklem hareketi iyi }\end{array}$ \\
\hline Tatminkâr & Kırık kaynaması iyi değil & Geçici topallık & $\begin{array}{c}\text { Artritik değişiklik var }(++), \\
\text { eklem hareketi tatminkar }\end{array}$ \\
\hline Kötü & Kırık kaynaması çok kötü & Kalıcı topallık & $\begin{array}{c}\text { Artritik değişiklik fazla }(+++), \\
\text { eklem hareketi kötü }\end{array}$ \\
\hline
\end{tabular}

\section{Bulgular}

Çalışma materyalini oluşturan 10 olgudan 6'sının (\%60) dişi, 4'dünün (\%40) erkek olduğu saptanmıştır.

On olgudan 1'inde bilateral femur kırı̆̆ı olmak üzere 11 kırıktan 8'inin (\%73) Femur, 3’ünün (\%27) tibia kırı̆ğ olduğu belirlenmiştir.

Belirlenen 11 kırığın anatomik bölgelerine göre 1'i (\%9) proksimal diyafizer femur, 4’ü (\%37) orta diyafizer femur kırığı, 4’ü (\%37) distal diyafizer femur kırığı, 2'si (\%18) orta diyafizer tibia kırığı olduğu gözlemlenmiştir ve 5’i (\%46) transversal kırık, 3’ü (\%27) oblik kırık, 3’ü de (\%27) parçalı kırık olarak sınıflandırılmıştır.

Karşı ekstermitedeki sağlıklı kemikten elde edilen radyografiler üzerinde yapılan ölçümler sonrası olgulara göre uygulanacak pinlerde 2'sinin (\%18) 6,0mm*130mm, 1'inin (\%9) 6,0mm*150mm, 1'inin (\%9) 6,0mm*160mm, 2'sinin (\%18) 6,0mm*170mm, 3'ünün (\%28) 6,0mm*190mm, 1'inin (\%9) 8,0mm*160mm, 1'inin (\%9) $8,0 \mathrm{~mm} * 180 \mathrm{~mm}$ boyutlarında olduğu belirlenmiştir (Tablo 3 ). 
Tablo 3: Olguların cinsiyet, yaş, uygulanan pin boyutları ve opere edilen kemik.

Table 3: Sex, age, pin sizes and operated bone informations of the cases.

\begin{tabular}{cccc}
\hline Olgu no & Cinsiyet ve yaş & $\begin{array}{c}\text { Kullanılan pin } \\
\text { boyutları }\end{array}$ & Kemik \\
\hline $\mathbf{1}$ & Dişi,10 aylık & $6,0 \mathrm{~mm} \times 170 \mathrm{~mm}$ & Femur \\
$\mathbf{2}$ & Dişi, 3 yaş & $6,0 \mathrm{~mm} \times 170 \mathrm{~mm}$ & Tibia \\
$\mathbf{3}$ & Erkek, 6 aylık & $6,0 \mathrm{~mm} \times 160 \mathrm{~mm}$ & Femur \\
$\mathbf{4}$ & Dişi, 6 aylık & $6,0 \mathrm{~mm} \times 130 \mathrm{~mm}$ & Femur \\
& & $6,0 \mathrm{~mm} \times 130 \mathrm{~mm}$ & Femur \\
$\mathbf{5}$ & Erkek, 4 yaş & $6,0 \mathrm{~mm} \times 170 \mathrm{~mm}$ & Femur \\
$\mathbf{6}$ & Erkek, 5 yaş & $6,0 \mathrm{~mm} \times 190 \mathrm{~mm}$ & Femur \\
$\mathbf{7}$ & Dişi, 9 aylık & $8,0 \mathrm{~mm} \times 160 \mathrm{~mm}$ & Femur \\
$\mathbf{8}$ & Erkek, 2 yaş & $8,0 \mathrm{~mm} \times 180 \mathrm{~mm}$ & Tibia \\
$\mathbf{9}$ & Dişi, 1 yaş & $6,0 \mathrm{~mm} \times 190 \mathrm{~mm}$ & Tibia \\
$\mathbf{1 0}$ & Dişi, 8 aylık & $6,0 \mathrm{~mm} \times 150 \mathrm{~mm}$ & Femur \\
\hline
\end{tabular}

Olgu 2, 9 ve 10 haricinde hiçbir olguda komplikasyona rastlanmadı. Olgu 2'de açık, enfekte ve maddi kayıplı kırık tespit edildi. Redüksiyon sonrasında fragmentler arasında meydana gelen boşluğa, reamer ile genişletme aşamasında elde edilen kompakt ve kansellöz kemik doku parçalarından oluşan kemik otogrefti uygulandı. Dikiş hattını korumak için postoperatif yumuşak bandaj uygulandı. Yara hattında herhangi bir enfeksiyon oluşmaması için günlük olarak bandaj değiştirildi ve yara bakımı yapıldı. 1 hafta sonunda yaradaki akıntı ve enfeksiyonun sonlandığı görüldü.

Olgu 10 haricindeki olgularda kırık iyileşmesinden sonra interlocking pinler, ilgili kemiğin medullasında bırakıldı ve postoperatif takip süresince komplikasyona neden olmadığı gözlendi.

Olgu 1'de düzenli yapılan postoperatif klinik ve radyografik muayeneler boyunca herhangi bir komplikasyon varlığına rastlanmadı ve 45 günün sonunda ilgili ekstremitede yürüyüşün ve ilgili ekstremiteye ağırlık vermenin oldukça iyi oldu gözlemlendi.

Olgu 3 (Şekil 1) 5 ve 7'de (Şekil 2) diyafizer femur kırı̆̆ tespit edildi. Postoperatif 45. günde yapılan radyografik muayenede kırık bölgesinde taşkın kallus oluştuğu belirlendi. Klinik muayenede ilgili ekstremitede ağrı ve hassasiyet olmadığı gözlendi.

Olgu 4'te bilateral orta diyafizer femur kırığı tespit edildi. Operasyon sonrasında sadece dikiş hattını korumaya yönelik pansuman uygulandığı için postoperatif dönemdeki konforun oldukça iyi olduğu tespit edildi.

Olgu 8'de 45 günün sonunda radyografik olarak kırık fragmentleri arasında kallus oluşumunun sorunsuz şekillendiği gözlendi. Ekstremitede klinik muayenelerde ağrı ve hassasiyet gözlenmedi.

Olgu 9'da distal ve proksimal vida deliklerinin sadece birer tanesine vida uygulandı. Böylece dinamik bir fikzasyon elde edildi. Postoperatif 45. gün alınan radyografilerde kırık bölgesinde enfeksiyon bulgusuna rastlandı. Buna yönelik antibiyotik tedavisine başlandı ancak sonraki süreçte olgunun takibi yapılamadı (Şekil 3).

Olgu 10'da distal diyafizer femur kırığı tespit edildi. 10. gün radyografisinde interlocking pinin Femur'un distal fragmentinin kranial duvarını kırıp kraniale doğru migre olduğu gözlendi. Bu olguda interlocking pin çıkartıldı ve kırığın tekrar sağaltımında Rush pini kullanıldı.

Modifiye Hannover Veteriner Yüksek Okulu küçük hayvan kliniği kırık sağaltımı değerlendirme skalasına göre olguların 6'sının çok iyi, 1'inin iyi,1'inin tatminkâr, 1'inin ise kötü olduğu tespit edildi, bir olgunun (olgu no 9) takibi yapılamadı (Tablo 4). 
Tablo 4: Kırık iyileşmesinin modifiye Hannover Veteriner Yüksek Okulu küçük hayvan kliniği kırık sağaltımı değerlendirme skalasına göre değerlendirilmesi.

Table 4: Evaluation of fracture healing according to Modified fracture treatment evaluation scale of Faculty of Veterinary Medicine Hannover.

\begin{tabular}{cc}
\hline Olgu no & $\begin{array}{c}\text { Modifiye Hannover Veteriner Yüksek } \\
\text { Okulu küçük hayvan kliniği kırık } \\
\text { sağaltım değerlendirme skalası }\end{array}$ \\
\hline $\mathbf{1}$ & Çok iyi \\
$\mathbf{2}$ & Çok iyi \\
$\mathbf{3}$ & Tatminkâr \\
$\mathbf{4}$ & Çok iyi \\
$\mathbf{5}$ & İyi \\
$\mathbf{6}$ & Çok iyi \\
$\mathbf{7}$ & Çok iyi \\
$\mathbf{8}$ & Çok iyi \\
$\mathbf{9}$ & Takibi yapılamadı \\
$\mathbf{1 0}$ & Kötü \\
\hline
\end{tabular}

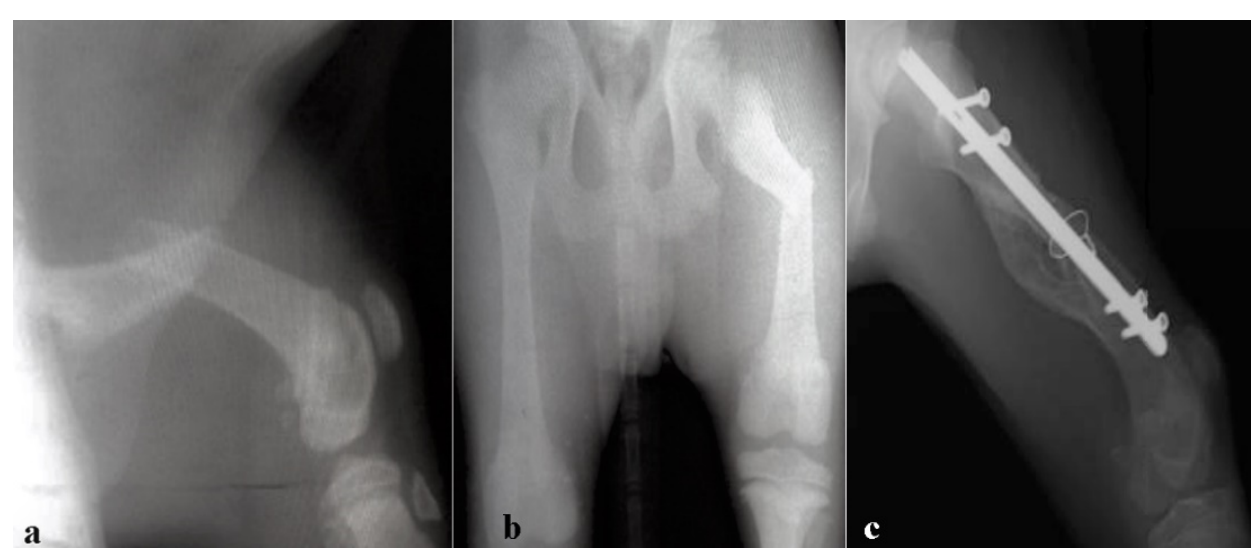

Şekil 1: Olgu 3' e ait radyografiler. a ve b) preoperatif, c) postoperatif 45. gün radyografileri. Figure 1: radiographs of case 3. $a$ and b) preoperative, c) postoperative $45^{\text {th }}$ day radiographs of case 3 . 


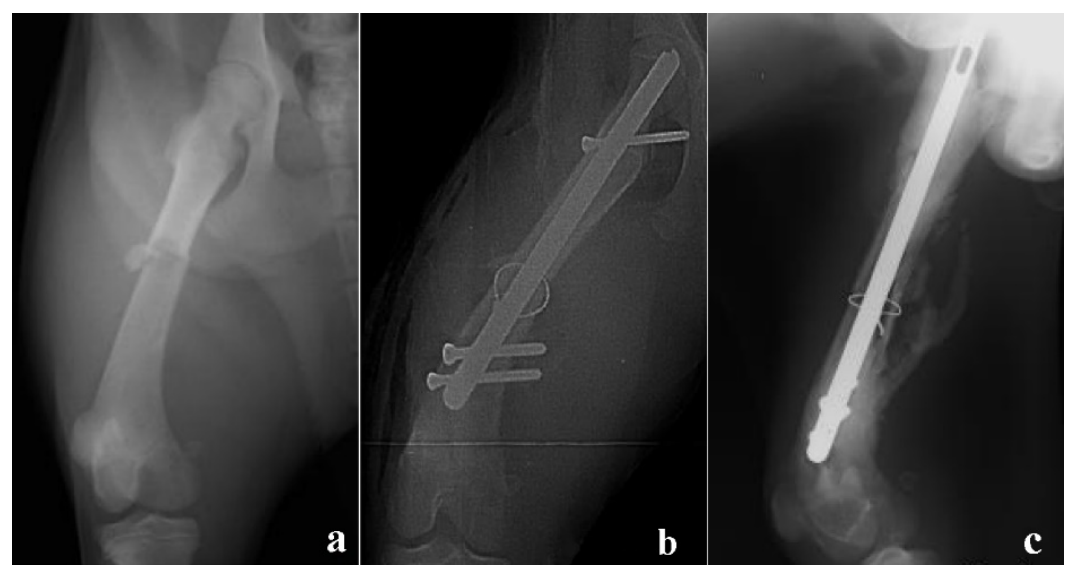

Şekil 2: Olgu 7'ye ait radyografiler. a) preoperatif, b) postoperatif $0, \mathrm{c}$ ) postoperatif 45 . gün radyografileri.

Figure 2: Radiographs of case no 7. a) Preoperative, b) postoperative 0, c) postoperative 45th day radiographs of case no 7.

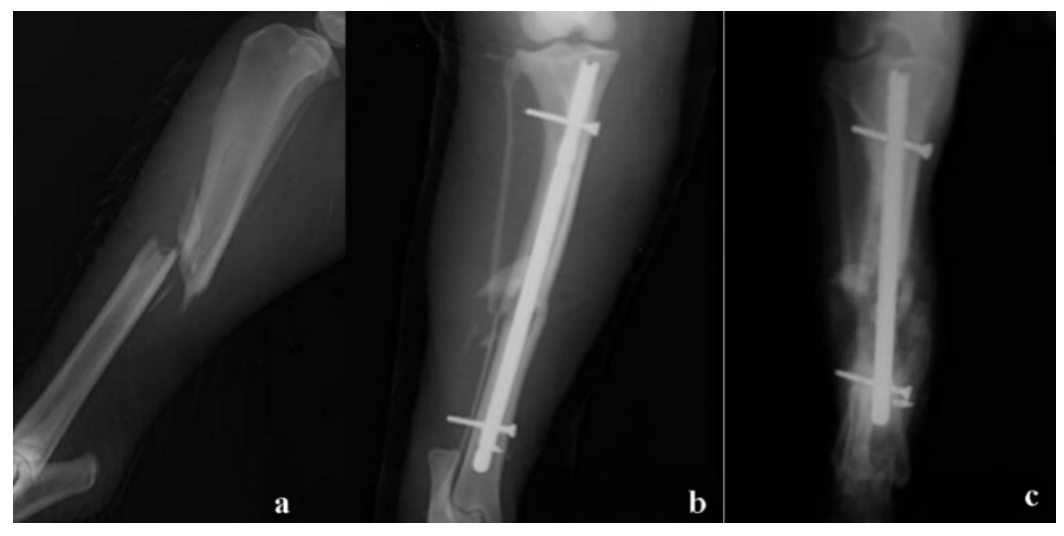

Şekil 3: Olgu 9'a ait radyografiler. a) preoperatif, b) postoperatif 0 , c) postoperatif 45. gün radyografileri.

Figure 3: Radiographs of case no 9. a) Preoperative, b) postoperative 0, c) postoperative $45^{\text {th }}$ day radiographs of case no 9.

\section{Tartışma ve Sonuç}

Veteriner ortopedide özellikle uzun kemik kırıklarının intramedullar olarak sağaltımında sıklıkla Steinmann pinler kullanılır. Steinmann pinlerinin uygulanması ve kırık iyileştikten sonra çıkarılması kolaydır. Kırık hattında oluşan bükülme kuvvetlerini belli ölçüde nötralize ederler, ancak makaslama, kompresyon, rotasyon gibi kuvvetlere karş1 etkisizdirler. Interlocking pinle sağaltım tekniğinin dairesel kesitli konvansiyonel pinlerden en önemli fark1, statik bir kilitleme yapıldığında, kırık hattında oluşabilecek tüm yıkıcı kuvvetleri nötralize etmesidir (2).

Bu klinik çalışmada interlocking pinler kullanılmış ve genellikle statik pozisyonda yerleştirilmiştir ( 8 olguda gelişen 9 kırıkta). Dinamik pozisyonda yerleştirilen olgular içinde ise bir olguda komplikasyon gözlenmiştir. Statik pozisyonda yerleştirilen interlocking pinlerin daha stabil bir fikzasyon sağladığ 1 , kırık hattında oluşabilecek güçleri normal bir intramedullar pin ve dinamik fikzasyona göre oldukça etkili şekilde önlediği ve komplikasyon riskini düşürdüğü gözlemlenmiştir.

Plak ve interlocking pin gibi materyallerde iyileşme sürecinde kallus oluşumu daha azdır (4). İnterlocking pinin avantajları arasında bu bilgi verilmiştir. Bu klinik çalışma sonuçları genel olarak kallus oluşumu yönünden değerlendirildiğinde, elde edilen veriler, literatür bilgi ile uyuşmaktadır. Sadece olgu no 3, 5ve olgu no 7'de taşkın kallus oluşumuna rastlanmıştır.

Interlocking pinler, kemik medullasının merkezinde olduğu için, plak gibi merkez dışında olan diğer materyallere oranla daha az komplikasyon (aseptik gevşeme vs.) oluşmaktadır (1). Bu klinik çalışma verileri değerlendirildiğinde literatür bilgiyle uyumlu olarak olgularda vida gevşemesine bağlı herhangi bir komplikasyona 
rastlanmadı. Postoperatif takip süresince radyografik muayenelerde, olguların tamamında herhangi bir vida gevşemesi gözlenmemiştir.

Interlocking pinler aksial hizalamayı başarılı şekilde sağlarlar (6). Ayrıca uzun kemiklerde açılanma oluşmasına engel olurlar $(1,6)$. İntramedullar pinlerle gerçekleştirilen klinik çalışmada izlenen olgularda aksial hizanın bozulması ve sonrasında gelişebilecek açılı kaynamaya bağlı bir komplikasyon bulgusuna rastlanmamıştır.

Interlocking pin uygulamalarında eğer açık redüksiyon tercih edilecekse plaklar ile karşılaştırıldığında, daha küçük bir operasyon yarası ve daha az diseksiyona ihtiyaç duyulur (3). Çalışma materyalini oluşturan olgulara uygulanan cerrahi yaklaşımlar baz alındığında çalışma verileri ile literatür veriler örtüşmektedir.

Yapılan değerlendirmeler sonucunda interlocking pin yönteminin, diğer intramedullar çivileme yöntemlerine göre temel olarak, kırık hattına etki eden tüm kuvvetleri nötralize etmesi, kırık iyileşmesi tamamlanıncaya kadar daha rijit bir fiksasyon sağlaması, postoperatif konforu arttırması gibi avantajları tespit edilmiştir.

Interlocking pin ile sağaltım yönteminin kullanılması, özellikle postoperatif bakımın önemli olduğu ve rijit bir fiksasyonun hedeflendiği olgularda önerilir. Uygulamada uygun boy ve çapta pin seçiminin dikkatle yapılması ve uygulanan vida ile kırık hattı arasındaki mesafenin özenle ayarlanması önemlidir. Çünkü komplikasyonların birçoğunun bunlara benzer teknik nedenlerden kaynaklandığı bilinmektedir.

Interlocking pinler köpeklerin femur ve tibia gibi uzun kemiklerin meydana gelen diyafizer kırıklarında kullanılabilir. Stabil olmayan kırıklar da dahil, fonksiyonel iyileşme sonuçları ve düşük komplikasyon oranlarıyla ilişkilendirildiğinde, uzun kemiklerin diyafizer kırıklarında interlocking pinlerin kullanımı desteklenmektedir.

Sonuç olarak interlocking pin ile sağaltım metodu, femur ve tibianın diyafizer kırıklarında alternatif bir sağaltım metodu olarak düşünülebilir.

\section{Kaynaklar}

1. Altunalmaz K (2003): Kırık sağaltımında interlocking pin kullanımı. İstanbul Üniv Vet Fak Derg, 29(2), 295-301.

2. Coughlan AR, Miller A (1998): Manual of Small Animal Fracture Repair and Management .17-45. In: S Roe (Ed), Biomechanical Basis of Bone Fracture and Fracture Repair, British Small Animal Veterinart Association, Cheltenham, United Kingdom.

3. Duhautois B (2003): Use of interlocking nails for diaphyseal fractures in dogs and cats: 121 cases. Vet Surg, 32, 8-20.

4. Durall I, Diaz MC (1996): Early Experience With The Use Of An Interlocking Nail For The Repair Of Canine Femoral Shaft Fractures. Vet Surg, 25, 397-406.

5. Fossum TW (2013): Small Animal Surgery. 1033-1105. In: Fundamentals of Orthopedic Surgery and Fracture Management, Mosby Inc., St. Louis.

6. Johnson AL, Dunning D (2005): Atlas of Orthopedic Surgical Procedures of the Dog and Cat. 132-133. In: Stabilizing a Comminuted Diaphyseal Fracture with an Interlocking Nail, Elsevier Inc., St. Louis, Missouri.

7. Kürüm B (2012): Interlocking nail stabilization of canine femoral fractures; clinical experience and results of the nineteen cases. Kafkas Univ Vet Fak Derg, 18(6), 1027-1034.

8. Nabholz K, Pozzi A, Schmierer PA, Smolders LA, Knell SC (2019): Safety and Accuracy of Minimally Invasive Long Bone Fracture Repair Using a 2.5-mm Interlocking Nail: A Cadaveric Feline Study. Vet Comp Orthop Traumatol, 32(5):351-361.

9. Stiffler KS (2004): Internal Fracture Fixation. Clin Tech Small Anim Pract, 19,105-113. 